\title{
La infortunada recepción de un emblema en el siglo xVIII
}

La fortuna no tiene ningún poder, salvo que los hombres la hacen diosa y la ponen en el cielo.

Juvenal, Sátiras

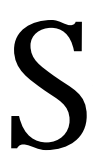

in LUGar a DUdAs 1767 FUE Un AÑo de infortunios para la sociedad novohispana. Los ojos de todos los grupos sociales observaban con sorpresa la aplicación de las reformas borbónicas. Una serie de innovaciones que incluía el reajuste del tributo de indios y mulatos, la creación del estanco del tabaco, el cobro de alcabalas, y el interés por crear un aparato estatal y frenar el avance de los grupos locales de poder. Al descontento inicial provocado por estas medidas siguió una indignación creciente, que generó una fuerte crisis política tras la expulsión de los jesuitas y desembocó en levantamientos armados en Guanajuato, San Luis Potosí y M ichoacán.

Pese a todo, durante los primeros meses de ese año, en medio de un ambiente tenso, la vida cotidiana de los habitantes del reino continuaba, y todos buscaban esparcimiento en los sitios públicos dedicados a tal fin. ${ }^{\mathrm{I}}$ Se podía encontrar refugio y olvido en las bebidas al cohólicas, aunque en diferentes establecimientos de acuerdo con su nivel social. ${ }^{2}$ Para los varones de las clases medias y nobles abrían sus puertas las vinaterías o tabernas (figura i); en ellas

I. Cfr. Juan Pedro Viqueira Albán, ¿Relajadoso reprimidos? D iversionespúblicasy vida social en la ciudad deM éxico durante el Siglo de las Luces, M éxico, Fondo de Cultura Económica, $200 I$.

2. Gustavo Curiel y Antonio Rubial, "Los espejos de lo propio: ritos públicos y usos priva- 
DOI: http://dx.doi.org/10.22201/iie.18703062e.2003.83.2402

56

DÉSIRÉE MORENO SILVA

se podía disfrutar de un buen vino C arlón o Pedro Jiménez, además de, en algunos casos, la compañía de mujeres "que no prostituidas enteramente buscan la oportunidad de que o las conviden o se incorporen con ellas, los que pasan 0 entran a beber", ${ }^{3}$ o bien de las Ilamadas "mujerzuelas de mala vida". ${ }^{4}$ Uno de estos establecimientos fue el escenario de la denuncia al Santo Tribunal de la Inquisición en el que se basa este trabajo de análisis y lectura de un mensaje emblemático.

Los clientes de la vinatería ubicada en el número is de la calle de la $\mathrm{M}$ onterilla deleitaban sus paladares con líquidos embriagantes a la sombra de la diosa Fortuna. Pues en el techo de esta accesoria se encontraba una pintura emblemática, denunciada al Santo 0 ficio, cuya principal protagonista era la veleidosa y cruel Tique.5 La noticia sobre la existencia de pintura popular que engalanaba los muros de accesorias, especial mente de pulquerías, durante el siglo xviri fue dada a conocer por M anuel Toussaint. ${ }^{6}$

Para el estudio de esta obra, desaparecida en la actualidad, recurriré a las breves descripciones hechas por sus contemporáneos. La más completa de ellas fue realizada por D omingo de Arrieta, comisionado por los inquisidores

dos en la pintura virreinal", en Pintura y vida cotidiana en M éxico, I650-1950, M éxico, Fomento Cultural Banamex/C onsejo N acional para la Cultura y las Artes, I999, p. 82.

3. Sonia Lombardo de Ruiz, Antología de textos sobre la ciudad de M éxico en el periodo de la Ilustración (I788-1792), M éxico, Instituto Nacional de Antropología e H istoria-D epartamento de Investigaciones H istóricas, 1982 (C olección Científica, Fuentes, H istoria Social, II3), p. 67.

4. Idem.

5. C fr. Salvador Cárdenas Gutiérrez, "La 'Rueda de la fortuna': un emblema del estado moderno", en H erón Pérez y Bárbara Skinfill (eds.), Esplendor y ocaso dela cultura simbólica, Zamora, EI Colegio de M ichoacán/C onsejo N acional de Ciencia y Tecnología, 2002, pp. 285-302.

6. M anuel Toussaint, Pintura colonial en M éxico, M éxico, Universidad N acional Autónoma de M éxico-Instituto de Investigaciones Estéticas, 1965, pp. 196-197. Sobre estos espacios en la Europa moderna, y la pintura que engalanaba sus muros, puede verse a Burke: "L as cervecerías eran otro de los espacios del arte popular. 'En estas casas', se nos ha contado, 'se podía ver la historia de Judith, Susana, D aniel en el foso de los leones, D imas o el milagro de Lázaro, todas ellas pintadas sobre la pared'. Las baladas satíricas eran muchas veces pintadas sobre la pared de las posadas, para que los clientes pudiesen cantarlas acompañando al baladista." Peter Burke, La cultura popular en la Europa moderna, M adrid, Altaya, I997, p. i68. O tra noticia sobre una pintura indecorosa en los muros de un mesón, también denunciada al Santo O ficio, tuvo lugar en el poblado mexicano de Tlapa en el siglo xviı. D enuncia de un Cristo con una guitarra en la mano, pintado en la pared, año de ı609. Archivo General de la N ación (AGN), Fondo Inquisición, vol. 284, exp. 95, fS. 790-790V. 


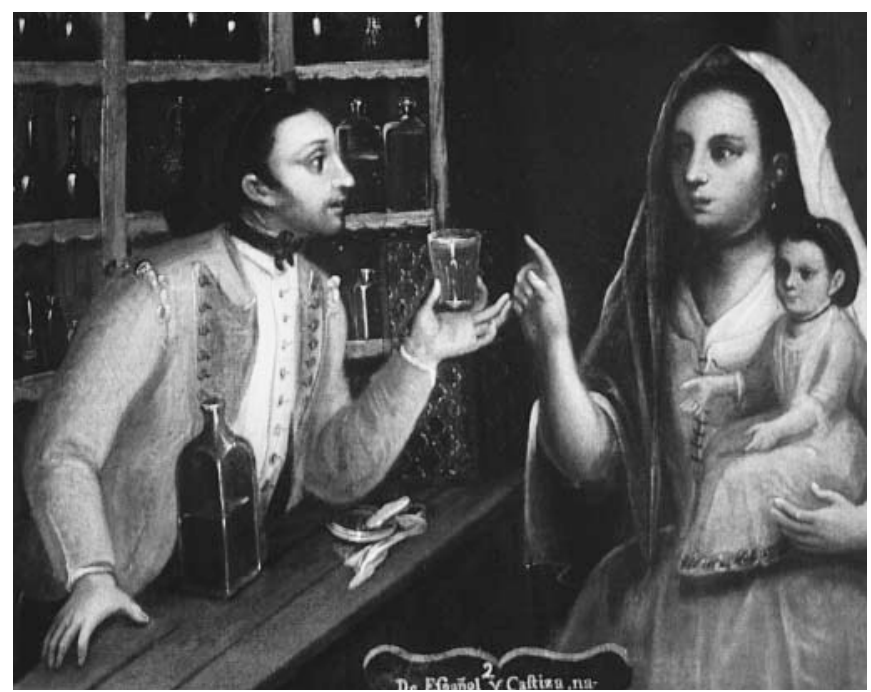

I. Anónimo, D e español y castiza nace castiza, siglo xviıI.

para examinarla. Esta manera de acercarse a una pintura forzosamente implica una pérdida del sentido, ya que una descripción verbal nunca podrá ofrecer todos sus detalles. Sin embargo, este tipo de documentos permite vislumbrar la compleja relación que se estableció entre la imagen y sus espectadores. Un público que no siempre la interpretó de manera similar, y lo que para algunos ojos causaba escándalo, para otros pasaba inadvertido.

La vista de ojos: el emblema y su reconocimiento

La acusación contra los autores del cielo raso de la vinatería fue recibida en el Tribunal el 26 de marzo de 1767.7 Ese mismo día los inquisidores ordenaron al doctor Arrieta que averiguara la veracidad de los hechos "poniendo en el mismo acto la diligencia de vista de ojos con la mayor especificación". Cumpliendo este mandato el calificador, en compañía del secretario Nicolás Abad, se

7. Denuncia de un cielo de vinatería, año de 1767 . AGN, Fondo Inquisición, vol. Io64, exp. 25 , fS. $33 \mathrm{I}^{-} 332$. 
encaminó hacia la accesoria ubicada en la esquina formada por las calles de la $M$ onterilla y la de don Juan $M$ anuel. Supongo que el procedimiento seguido en esta diligencia fue que Arrieta vio y "leyó" en voz alta la pintura, mientras Abad se esforzaba por escribir con rapidez las ideas expresadas por su compañero. El reconocimiento de esta "poesía mural"8 fue el siguiente:

pintado en cotencio una figura de la fortuna montada en un caballo, hollando el mundo con varias monedas y alhajas, desde las que partiendo el mundo y por entre los pies del caballo sale un rótulo que dice: 0 mnia peribunt et prevalet nihil. Y al lado derecho de dicha figura están pintados cuatro personajes, representando en sus trajes y colores las cuatro partes del mundo, arrodilladas en ademán de súplica. Al lado izquierdo, en ademán de tener la cauda y seguir a la fortuna están pintados por su orden: un obispo con mitra y pectoral, un religioso franciscano, un doctor borlado, una mujer y un hombre seculares. Encima de dicha figura de la fortuna está, entre nubes, el medio cuerpo de un hombre con traje talar; cuya mano derecha tiene asido el moño de la fortuna...

Esto en lo que se refiere a la pictura y al mote. D el epigrama, Abad escribió:

a los dos lados del dicho cielo, en la parte de afuera, están dos coplas que el tenor de la primera es: "Vulcano atrevido, intenta la fortuna combatir, sin llegar a discurrir que el moño se le revienta". Y el otro dice: "La fortuna es menester el saberla conservar, pues sólo por ser mujer, al mejor tiempo ha de dar que sentir y padecer".

Es claro que en esta enumeración de las figuras contenidas en la pintura ya hay una representación conceptual que las interpreta, asignando a cada una de ellas una carga simbólica específica; pues toda imagen deviene siempre en representación interna, es decir, en imago. ${ }^{9}$ Intentaré, con base en su narración, establecer la relación que existía entre las figuras que conformaban este elaborado discurso visual.

8. Término utilizado por el investigador J. Simón Díaz, "La poesía mural del Siglo de O ro: su proyección en universidades y colegios", en Estudios sobre el Siglo de 0 ro. H omenaje a Francisco Yndurain, M adrid, Editora Nacional, 1984, pp. 479-499.

9. Fernando Rodríguez de la Flor, Emblemas: Lecturas de la imagen simbólica, M adrid, Alianza, 1995, p. I3. 


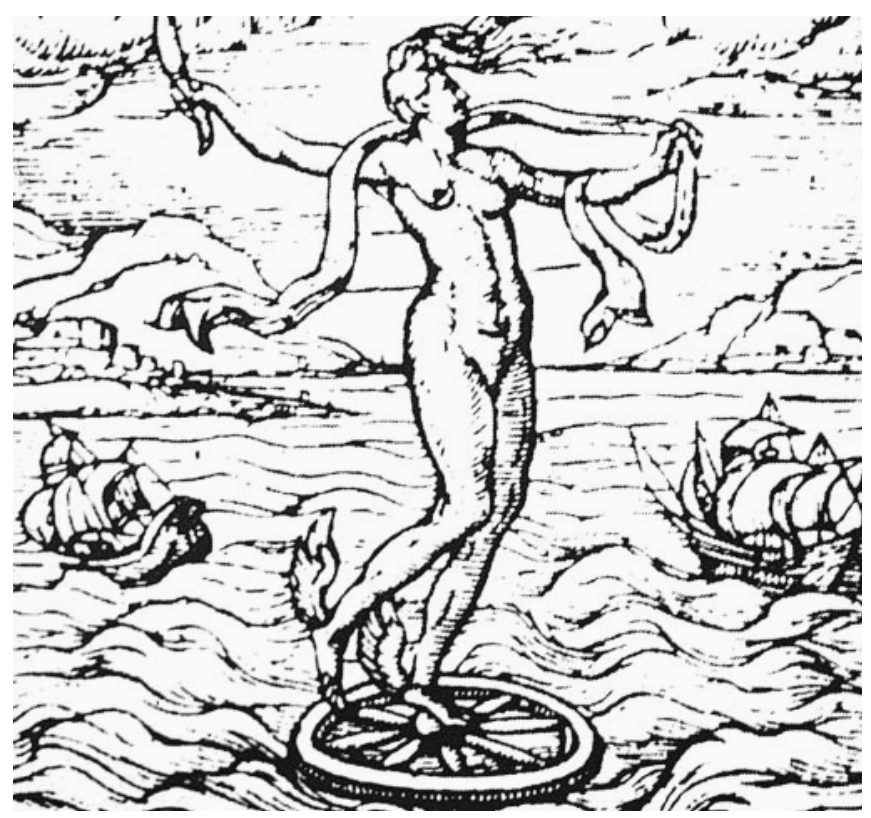

2. Alciato, Emblematum Liber, emblema I2I, In 0 ccasionem.

D e pompas y vanidades, de reyes y cortejos

Loca, ciega, bruta, desnuda, con una gran vela, navaja y cornucopia, sobre una bola 0 un timón se desliza fácilmente la fortuna (figura 2). Loca porque favorece a los atrevidos y da la espalda a los hombres prudentes. Ciega ya que derriba al merecedor de premios y levanta al que debiera abatir. Bruta, pues no sabe distinguir entre el digno y el que no lo es (figura 3). C on la navaja, corta la felicidad; mediante la cornucopia reparte la riqueza y los bienes terrenales. La bola es símbolo de su inestabilidad, con la vela y el timón gobierna el curso de las vidas humanas. ${ }^{\text {IO }}$

Io. Juan F. Esteban Lorente, “La ocasión o 'Parte de fortuna' como tema astrológico en los palacios de la Farnesinia (Roma) y Zaporta (Zaragoza)", en Santiago Sebastián (coord.), Actas del I Simposio Internacional de Emblemática, Teruel, Instituto de Estudios Turulenses, 1994, pp. 805822. CesareRipa, I conología, Venecia, Cristóforo Tomasini, I645, t. I, libro segundo, pp. 226-228. 


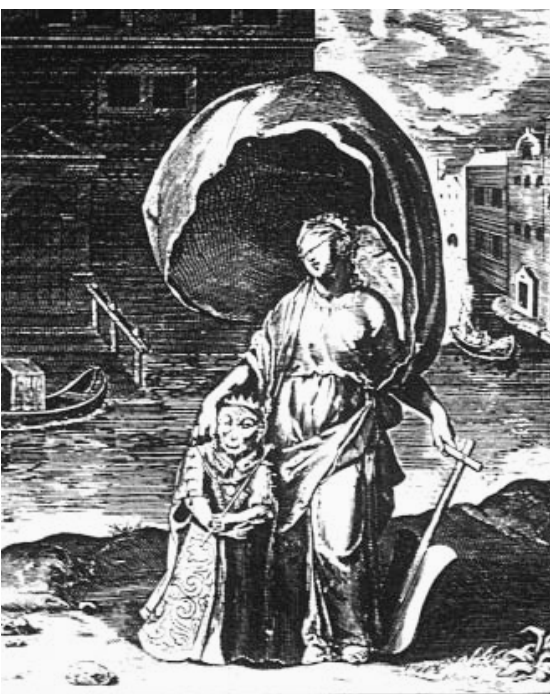

3. 0 tto Vaenius, Emblemata, I669, emblema 5I, La fortuna no muda el linaje.

Ejerce su gobernaculum sobre el mundo que, en este caso, fue representado por las cuatro partes, en clara alusión a la universalidad de su dominio (figuras 4, 5, 6 y 7). La estrecha relación que mantiene con lo mundano la asocia frecuentemente a la corte: un microcosmos de inestabilidad perenne, donde reparte caprichosamente honores y de igual forma los arrebata (figura 8). Al dirigir todas las intrigas cortesanas puede fácilmente apropiarse de la corona. En su papel de reina es acompañada por súbditos y sirvientes que cumplen todos sus deseos, entre ellos pueden encontrarse a príncipes, duques, condes, cardenales y obispos.

Este triunfo de la fortuna y su poder sobre los destinos humanos fue plasmado por medio de la rueda y las inscripciones regnabo, regno, regnavi y sum sine regnum (figura 9). Con esta imagen se pretendía inducir a los hombres a reflexionar sobre la vanidad de los placeres y exhortarlos para alcanzar la virtud, que es la única que permanece. ${ }^{\text {II }}$

H oward R. Patch, The Goddes Fortuna in M ediaeval Literature, Cambridge, $\mathrm{H}$ arvard University Press, 1927. Jacqueline Champeaux, Fortuna: recherches sur le culte de la fortune à Rome et dans le monde romain des origins à la mort de César, Roma, École Française de Rome, 1982. Jerold C. Frakes, The Fate of Fortune in the Early M iddle Age, Leiden, E.J. Brill, 1987.

II. Santiago Sebastián, Emblemática e historia del arte, M adrid, Cátedra, 1995, p. 292. 


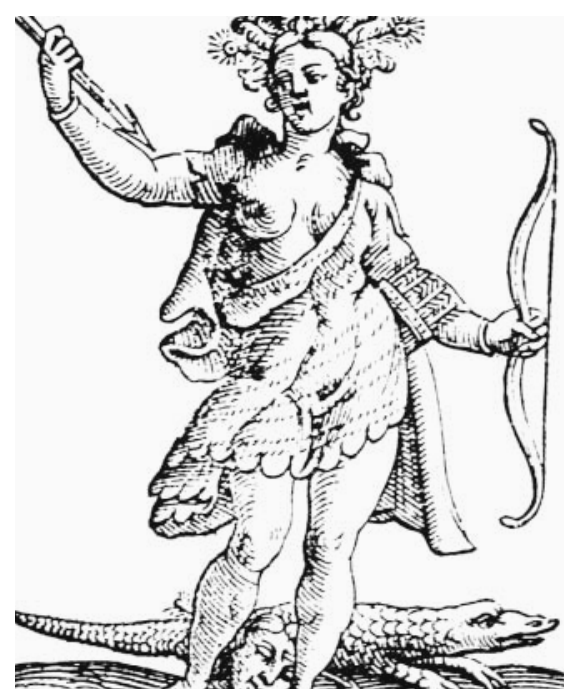

4. Cesare Ripa, Iconología,

Venecia, i645. Alegoría de América.

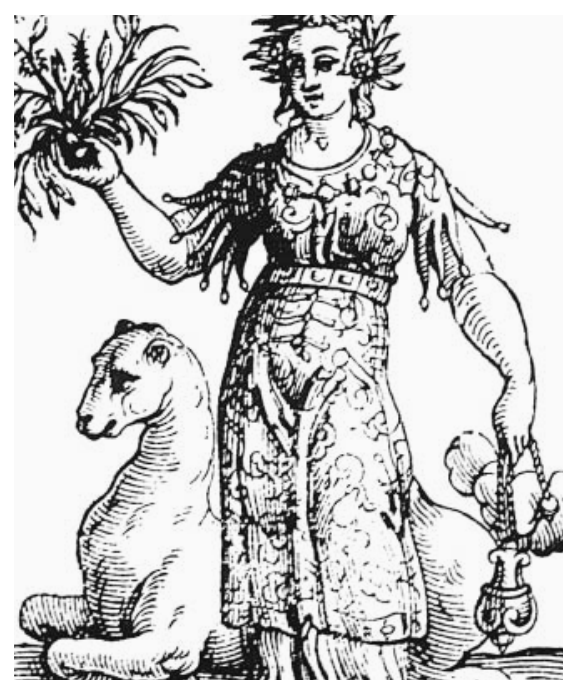

6. Cesare Ripa, I conología, Venecia, 1645. Alegoría de Asia.

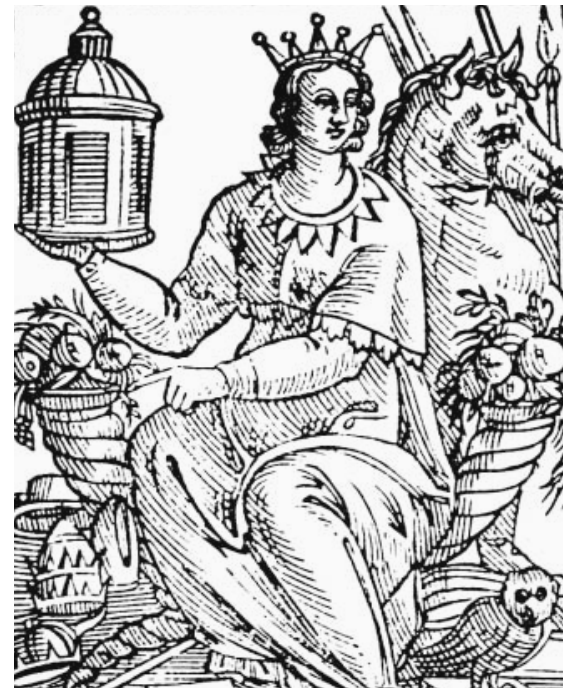

5. Cesare Ripa, I conología, Venecia, I645. Alegoría de Europa.

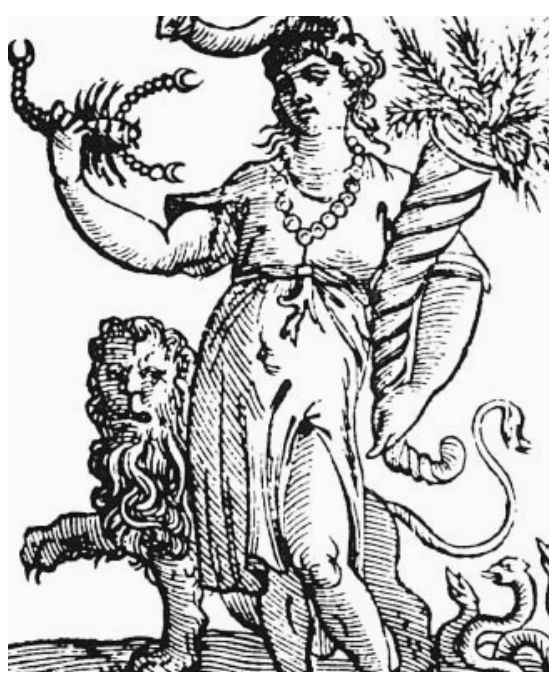

7. Cesare Ripa, Iconología, Venecia, I645. Alegoría de África. 


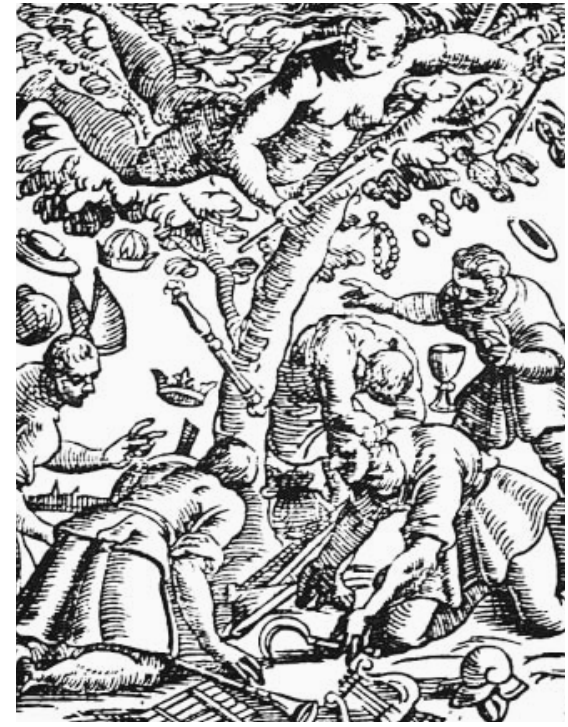

8. Cesare Ripa, I conología, Venecia, I645. La fortuna.

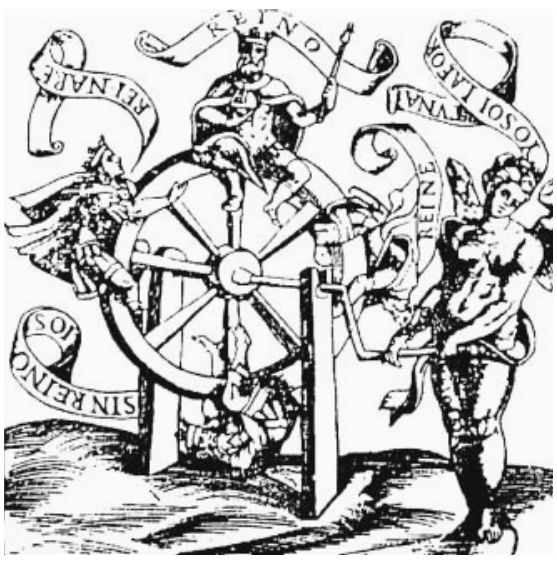

9. Anónimo, La rueda dela fortuna, grabado español, siglo xviI.

D esde Plutarco se desarrolló la oposición entre lo variable del destino humano, representado por la Fortuna, y la Sabiduría o Prudencia; lucha alegórica que puede verse en la xilografía que ilustra la obra de C harles Bovelle, D e Sapiente (figura ro). En el siglo xvi fue muy popular la confrontación entre el vir fortunatus (el hombre que espera instintivamente el momento favorable) y el vir prudens (aquel que somete sus acciones a la razón), cristalizada en el emblema 98 de Alciato, Ars naturam adiuvans (el arte ayuda a la naturaleza; figura II). ${ }^{\text {I2 }}$

Considero que la Prudencia y la laboriosidad fueron representadas en el cielo raso de la vinatería por un dios cojo de ambos pies "cuya falta de suerte, combinada con los poco corrientes dones de buen humor y facilidad de inventiva, le convirtieron en la más ridícula y al mismo tiempo la más amable figura del Panteón pagano". ${ }^{13}$ M e refiero a H efesto o Vulcano, y a la historia

I2. Idem, pp. 293-294.

I3. Erwin Panofsky, "La historia primitiva del hombre en dos ciclos de pinturas de Piero di Cósimo", en Estudios sobre iconología, M adrid, Alianza, 1998, p. 47. 
Io. Charles de Bovelle,

De Sapiente, París, isıo. Altercatio entre la Fortuna y la Sabiduría.

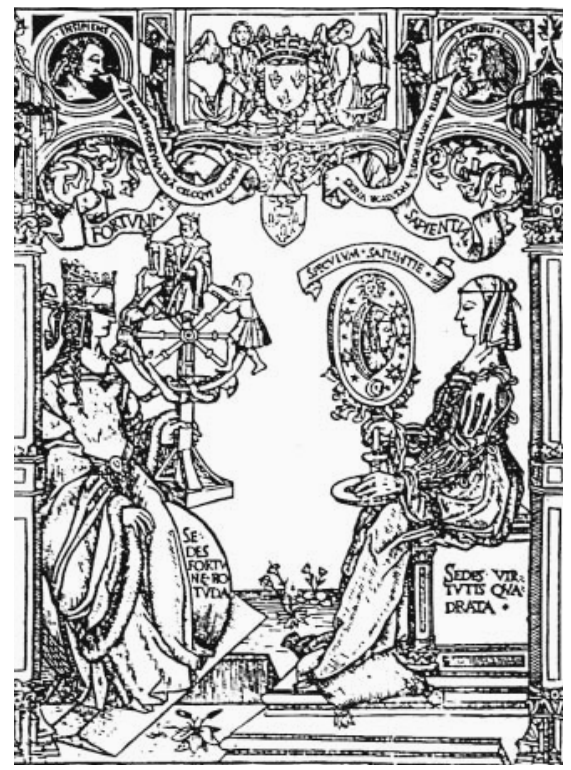

que durante mucho tiempo - según 0 vidio- fue la más comentada en todo el O limpo: ${ }^{14}$ el adulterio de su esposa Venus con $M$ arte. La narración que del hecho hizo H omero es la siguiente:

El Sol, que vio el amoroso acceso [entre Ares y Afrodita], fue en seguida a contárselo a H efesto; y éste, al oír la punzante nueva, se encaminó a su fragua, agitando en lo íntimo de su alma ardides siniestros [... ] y fabricó unos hilos inquebrantables para que permanecieran firmes donde los dejara. D espués que [... ] construyó esta trampa, fuese a la habitación en que tenía el lecho y extendió los hilos en círculo y por todas partes alrededor de los pies de la cama y colgando de las vigas; como tenues hilos de araña que nadie hubiese podido ver [... ] por haberlos labrado aquél con gran artificio. ${ }^{\text {Is }}$

Estos inquebrantables hilos son seguramente a los que se hace referencia con el moño que sostiene Vulcano para asir a la Fortuna; sin embargo, los artifi-

I4. Publio Nasón O vidio, M etamorfosis, M adrid, Alianza, 200I, p. I5o.

I5. H omero, La 0 disea, M éxico, Porrúa, I99I, pp. 53-54. 
64 DÉSIRÉE MORENO SILVA

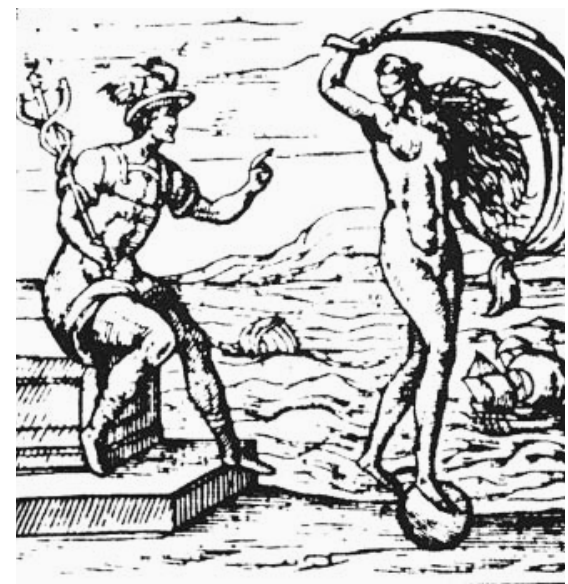

II. Alciato, Emblematum Liber, emblema 98, Arsnaturam adiuvans.

ciosos lazos fabricados por el prudente $\mathrm{H}$ efesto, si bien encadenaron a los amantes, no fueron capaces de atrapar a la inestable diosa.

El adulterio o la tragedia deamor fueinterpretada en tono moralizante por el comentarista español de las M etamorfosis de 0 vidio, Sánchez de Viana, para quien esta fábula intentaba "persuadir a los hombres a bondad y justicia, entereza en la vida y costumbres" y además demostraba que D ios castiga con facilidad a los malos, "aunque en los ojos de los hombres sean tenidos por muy poderosísimos". ${ }^{16}$ Esta historia inducía a llevar una vida virtuosa, pues sin importar su poder en esta tierra, al cabo los impíos recibirían el castigo merecido.

El tema fue retomado por el emblemista Paolo M accio, quien en el siglo xvir representó a Hefesto trabajando en la fragua, mientras Afrodita danzaba con las ninfas; M accio identificó a Venus, que perdía el tiempo en vanidades, con el malum pessimun (figura 12 ). ${ }^{17}$

Así la virtud de Vulcano permanece frente a lo inestable del mundo. Sin embargo, en la pintura mural, el símbolo de su trabajo, los lazos o cadenas, son frágiles y se rompen. Pareciera que el sentido del emblema es demostrar la superioridad de la Fortuna sobre la Prudencia.

I6. Santiago Sebastián, op. cit., p. I85.

I7. I dem Publio N asón O vidio, Transformaciones, anotaciones de Sánchez de Viana, Valladolid, 1589, p. 82. 
I2. Paolo M accio, Emblemata, emblema 28, Uxor mala, malum pessimum.

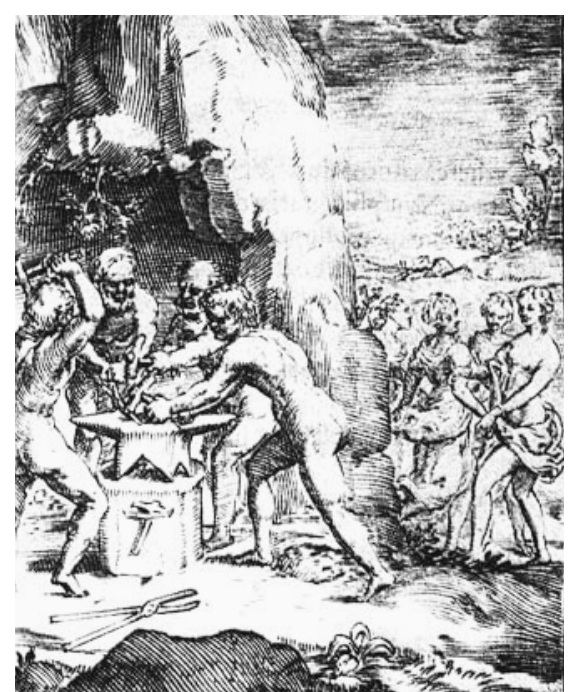

El triunfo del vir fortunatus sobre el vir prudens parece ser confirmado por el segundo verso del epigrama, cuya fuente la encuentro en Maquiavelo, quien escribió: "considero que es preferible ser impetuoso y no cauto, porque la fortuna es mujer y se hace preciso, si se la quiere tener sumisa, golpearla y zaherirla. Y se ve que se deja dominar por éstos antes que por los que actúan con tibieza. Y, como mujer, es amiga de los jóvenes, porque son menos prudentes y más fogosos y se imponen con más audacia". ${ }^{8}$

El cielo de la taberna presentaba a la Fortuna triunfante como emperatriz del mundo, gobernando los destinos de todos los hombres, sin distinción de profesión ni género. Su poder era infinito y nada se le oponía, ni siquiera la Prudencia, virtud propia del quehacer político y el arte del buen gobierno. Así que ¿tenía razón el emblema? ¿frente a la vanidad del mundo, nada permanece?

Sobre la vida humana

La voluble Fortuna, su inestabilidad y poca firmeza aparecen asociadas desde la Edad M edia con el desprecio del mundo. Varios autores españoles del siglo $\mathrm{xv}$ enfatizaron en sus escritos la característica mutabilidad y su influencia en 
DOI: http://dx.doi.org/10.22201/iie.18703062e.2003.83.2402

66

DÉSIRÉE MORENO SILVA

las desgracias de los hombres. ${ }^{19}$ El tono melancólico de estas obras, bajo la influencia del neoestoicismo, pretende despertar en los lectores un desprecio por los bienes de la vanidad.

Sin embargo, este profundo pesimismo, que se presenta como una visión angustiosa del desengaño del mundo, de la fugacidad de las riquezas y de la vanidad de los honores, ya que la vida humana deviene en muerte, es, al mismo tiempo, una propuesta de lucha infatigable por alcanzar los bienes imperecederos de las virtudes cristianas, convirtiéndose así en una fuente inagotable de optimismo.

La figura pesimista por excelencia es $\mathrm{H}$ eráclito, el solitario filósofo de Éfeso que sintetizó la idea del fluir continuo de las cosas y la inestabilidad del mundo en la sentencia "Todo pasa y nada permanece"; en estrecha relación con el mote de la pintura emblemática del techo: 0 mnea peribunt et praevalet nihil (todos perecemos y nada permanece). Con el mismo sentido aparecen las palabras praevalet nihil en el salmo 48 de la Vulgata:

¡O íd esto, pueblos todos! ¡Prestad oído todos los moradores del orbe: Plebeyos y nobles, ricos y pobres juntamente! [... ] Nadie puede rescatar al hombre de la muerte [... ] el hombre no perdura en su esplendor, es semejante a las bestias, que perecen [... ] Porque a su muerte nada se llevará consigo, ni le seguirá su gloria.

Las reflexiones de H eráclito sobre la vida no pasaron desapercibidas para la emblemática. Alciato las retomó en su emblema is2: In vitam humanam (figura I3), donde se encuentra al desencantado filósofo con otro colega que sostenía una postura diferente frente a la existencia terrena. D emócrito oponía a la queja por los vicios humanos la tranquilidad del ánimo, de allí que Alciato comente: "Llora, H eráclito, ahora más de lo que sueles, las penalidades de la vida humana, pues los males abundan cada vez más en ella. T ú por el contrario, D emócrito, redobla más que antes tus carcajadas, la vida se ha

19. Como Ruy Páez de Ribera, Pedro Salinas o fray Diego de Valencia. Cfr. Juan de Dios Mendoza, Fortuna y providencia en la literatura castellana del siglo XV, Madrid, Boletín de la Real Academia Española, 1973. La influencia del principio filosófico estoico del continuo movimiento del mundo por el cual se afirma que todo cambia y nada permanece estuvo presente como una de las principales temáticas de la ética neoestoica y senequista del pensamiento barroco. Cfr. Christian Bouzy, "N eoestoicismo y senequismo en los emblemas morales de Juan de O rozco", en Rafael Zafra y José Javier Azanza (eds.), Emblemata aurea. La emblemática en el arte y la literatura de Siglo de O ro, M adrid, Akal, 2000, pp. 69-78. 
I3. Alciato, Emblematum Liber, emblema 152 , In vitam humanam.

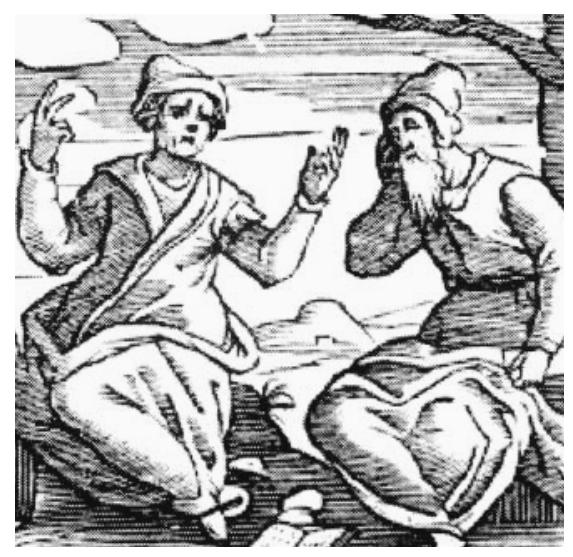

vuelto dichosa". Ver miseria y llorar, o ver actitudes ridículas y reír; debate intenso que se desarrolló en el barroco y llegó a tierras novohispanas por influencia jesuita en i685, con la publicación del libro H eráclito defendido por el P. Antonio deVieyra. ${ }^{20}$

En cuanto al cielo de la vinatería es muy interesante que el mote o rótulo en latín, como es descrito, se relacione con el temperamento de H eráclito. $M$ ientras que el espacio donde se alberga, una vinatería, esté asociado a Demócrito y algunas de sus representaciones plásticas, que lo muestran acompañado de un vaso de vino o de una vid, por el influjo del licor en la al egría y la risa de los hombres. Así se establece entre los diferentes niveles de la vinatería una oposición jerárquica entre dos formas de ver el mundo. En el nivel superior del cielo, ocupado por el emblema, estaba la postura melancólica y pensativa de $\mathrm{H}$ eráclito, mientras que en el nivel inferior o terrestre, ocupado por los clientes, se podría ubicar al ebrio y juguetón D emócrito.

\section{M odos de ver}

¿C uáles fueron los distintos tipos de recepción que este artefacto cultural encontró entre los diferentes miembros de la sociedad virreinal que tuvieron la oportunidad de observarlo? U na pregunta que quizá nunca se pueda contes- 
tar cabalmente y, sin embargo, me atrevo a afirmar que no todos veían lo mismo o lo interpretaban de modo similar. La manera en que los espectadores ordenan su experiencia visual está permeada por múltiples variables históricas y sociales que complementan la información recibida a través del estímulo visual. ${ }^{21}$ Pues el sentido de la imagen simbólica no se da "nunca en soledad abstracta y fija, sino que en realidad [... ] siempre [es] el resultado de una formación discursiva, que constantemente se encuentra sometida a correcciones del contexto social y a presiones del psiquismo del espectador". ${ }^{22}$ Un ejemplo lo tenemos en las diferentes reacciones que provocó esta imagen.

\section{La mirada escrupulosa}

El primer vistazo que hay sobre esta pintura se encuentra consignado en la denuncia que realizó Antonio Ruiz de Q uinto. Para disculparse frente a las autoridades por su estancia en un lugar de dudosa moral afirmó haberla visto por "casualidad" en la accesoria mencionada. Interpretó el sentido de las figuras apoyándose en el epigrama que las acompañaba, concluyendo que se trataba del dios Vulcano a caballo con una gran capa, cuya cauda levantaban, a modo de pajes, un obispo, un religioso franciscano, un clérigo y otros personajes a los que no les dio importancia. No mencionó, no vio o no supo interpretar las figuras de las cuatro partes del mundo y de H efesto.

En cuanto al mote comentó: "pude persevir, salvo yerro, está un rótulo con un texto de la Escriptura". La identificación de figuras pertenecientes a la jerarquía eclesiástica y la interpretación del texto como una cita de la Biblia le provocaron un sentimiento de escrúpulo. En cumplimiento de su obligación como hombre religioso, escribió una carta con sus observaciones sobre la perturbadora obra.

Es interesante que un hombre de mediana cultura, como Antonio Ruiz de Q uinto, quien por lo menos sabía leer y escribir, interpretara erróneamente el emblema. Si este personaje es el homónimo, de oficio librero, que años atrás realizó un inventario de la biblioteca del fallecido bachiller M iguel de Arana para la Inquisición, su confusión entre las figuras de la Fortuna y Vulcano re-

2I. M ichael Baxandall, Pintura y vida cotidiana en el Renacimiento, Barcelona, Gustavo Gili, 2000, p. 60.

22. Fernando Rodríguez de la Flor, op. cit., p. i3. 
sulta sorprendente. ${ }^{23}$ La familia Q uinto contaba con una de las librerías más importantes de la ciudad de M éxico a mediados del siglo xviII. Entre sus estantes se encontraban varios autores de literatura emblemática, como Alciato, Isidro de Sariñana y Cuevas, D iego de Saavedra y Juan de Solórzano, además de diferentes ediciones de las $\mathrm{M}$ etamorfosis de 0 vidio. ${ }^{24}$

\section{La mirada erudita}

D e corte más intelectual es la relación que mencioné en un principio, realizada por el calificador, doctor y fraile dela orden de predicadores: D omingo Pedro de Arrieta. Los calificadores eran expertos en teología y otras materias, designados por la Inquisición para examinar los objetos delatados y emitir un juicio detallado de los mismos. Por supuesto que la opinión de Arrieta no era del todo objetiva, y es posiblequeen su interpretación de la imagen existan algunos errores, como lo atestigua el hecho de que afirme que el traje de Vulcano era talar: ¿cómo pudo saber el dominico que esta figura vestía una túnica hasta los talones si, como él mismo menciona, sólo estaba pintado de medio cuerpo?

\section{La mirada que censura}

El 3 de abril de dicho año, los inquisidores echaron un vistazo a la descripción realizada por el señor calificador, y a primera hora de la mañana mandaron a N icolás Abad que intimara al dueño de la vinatería a borrar toda figura que pudiera ser escandalosa: el obispo, el fraile y el rótulo en latín. Su acción estaba sancionada por la regla decimosegunda del Índice expurgatorio, la cual abarcaba toda manifestación gráfica:

Asimismo se prohíben todas y cualesquier imágenes, retratos, figuras o hechos, empresas, invenciones, máscaras, representaciones y medallas, en cualquier materia queestén estampadas, pintadas, dibujadas, labradas, tejidas, figuradas o hechas, que sean irrisión de los santos y en desacato e irreverencia suya y de sus imágenes, reliquias o milagros, hábitos, profesión o vida. Y asimismo las que fueran en desacato

23. Inventario de los bienes del bachiller M iguel de Arana, año de I732. AGN, Fondo Inquisición, vol. 839 , exp. 23, fS. 28I-284.

24. Lista de libros presentada por don José Q uinto, librero en la calle de la M onterilla, año de I759. AGN, Fondo Inquisición, vol. 992, exp. 6, fs. 4I-202. 
de la Santa Sede A postólica, de los romanos pontífices, cardenales y obispos y de su estado, orden, dignidad y autoridad, claves y poderío espiritual. ${ }^{25}$

En este caso, los censores también se basaron en la noción de figura escandalosa, materia consignada en algunos tratados de pintura, donde se establecía una diferencia entre escándalo activo y pasivo. El primero lo ocasiona la acción per se, es decir, por su misma naturaleza; mientras que el pasivo era per accidens, ocasionada por la flaqueza del espectador, sin que la causa del escándalo fuera provocada por el pintor o su obra. ${ }^{26}$ Esta sutil distinción aparece registrada en varios expedientes sobre censura inquisitorial del siglo xviII. Sin embargo, la acción ejercida contra las imágenes denunciadas fue la misma: la eliminación de una de sus partes o de su totalidad.

Una mirada distraída

El propietario de la vinatería acató con humildad la decisión tomada por los inquisidores y agregó que inmediatamente haría lo que se le mandaba. Reconoció la piedad que el tribunal manifestaba para su inadvertencia, es decir, se disculpó por no advertir el peligro de la pintura por ver, con otros ojos y otra intención, el emblema de la Fortuna con el que adornaba su establecimiento.

\section{Consideracionesfinales}

D urante lo que se ha denominado el declive de la cultura emblemática novohispana, ésta se extendió más allá de la página impresa y se filtró a otros ámbitos. ${ }^{27}$

25. M onelisa Pérez-M archand, D os etapas ideológicas del siglo XVIII en M éxico a través de los papeles de la Inquisición, M éxico, El Colegio de M éxico, 1945, p. 190.

26. Antonio Palomino de Castro y Velasco, El museo pictórico y escala óptica, M adrid, Viuda de Juan García Infançon, I724, p. 95.

27. Cfr. Víctor M ínguez, “I747-I808: Agonía emblemática. El ocaso de la cultura simbólica en la fiesta novohispana”, en H erón Pérez M artínez y Bárbara Skinfill (eds.), Esplendor y ocaso de la cultura simbólica, Zamora, El Colegio de M ichoacán, 2002, pp. 303-315. Víctor M ínguez, Emblemática y cultura simbólica en la Valencia barroca. Jeroglíficos, enigmas, divisas y laberintos, Valencia, Edicions Alfons el M agnànim, 1997, p. 83. Federico Revilla, "M aterial emblemático en la vía pública: su presencia en una de las fiestas dieciochescas de Barcelona", en Víctor M ínguez (ed.), Del libro de emblemas a la ciudad simbólica. Actas del III Simposio Internacional de Emblemática Hispánica, Castellón de la Plana, Universitat Jaume I, 2000, vol. I, pp. 325-326. 
DOI: http://dx.doi.org/10.22201/iie.18703062e.2003.83.2402

La "emblemática aplicada" ${ }^{28}$ contribuyó a la persistencia de presupuestos filosóficos de claro sentido neoestoico en la cultura virreinal, que tuvieron una enorme vigencia aún en la segunda mitad del siglo xviII. ${ }^{29}$

En esta época, el emblema multiplicó sus reflexiones de sabiduría práctica a espacios cotidianos como el estrado30 0 la taberna, encontrando refugio en ambientes profanos y relajados. Fue utilizado como un elemento popular y divertido para fijar en la mente del espectador su sentido didáctico y moralizante, y logró sobrevivir en el medio ilustrado del Siglo de las Luces.

Para el periodo que nos ocupa, la ciudad de M éxico contaba con 4Io vinaterías distribuidas en toda el área urbana. ${ }^{3 \mathrm{I}} \mathrm{C}$ abe preguntarse cuántas de ellas habrán ostentado en sus muros pintura emblemática. En estos lugares la mezcla de lo sagrado y lo profano era frecuente, desde los nombres con el que se conocía a al gunas de ellas como "Los cinco señores", hasta el recurso, utilizado también por comerciantes de otros giros, de asociar sus productos a las imágenes sagradas con el propósito de obtener mayores ventas. ${ }^{32}$ Los habitantes de la ciudad buscaban la protección de la providencia en sus negocios, como buscaban la ayuda de la Fortuna en asuntos amorosos y en los juegos de azar, actividades también desarrolladas en las vinaterías, según lo atestigua la

28. Cfr. Giuseppina Ledda, "Estrategias y procedimientos comunicativos en la emblemática aplicada (fiestas y celebraciones, siglo xviI)", en Rafael Zafra y José Javier Azanza (eds.), Emblemata aurea. La emblemática en el arte y la literatura del Siglo de O ro, M adrid, Akal, 200o, pp. 25I-262.

29. Véanse las obras de Santiago Sebastián, Emblemática e historia del arte, pp. 259-284. I conografía e iconología del arte novohispano, M éxico, Grupo Azabache, 1992. "Los libros de emblemas: uso y difusión en I beroamérica", en Juegos de ingenio y agudeza. La pintura emblemática en la N ueva España, M éxico, Consejo N acional para la Cultura y las Artes, 1994, pp. 64-69.

3o. Especialmente a través de la pintura en biombos, cfr. M arita M artínez del Río de Redo, "Los biombos en el ámbito doméstico: sus programas moralizadores y didácticos", en Juegos de ingenio y agudeza. La pintura emblemática en la N ueva España, M éxico, Consejo Nacional para la Cultura y las Artes, 1994, pp. 133-I45, y Rosario Inés Granados Salinas, "H acia la puerta norte del salón del estrado", en H erón Pérez y Bárbara Skinfill (eds.), Esplendor y ocaso de la cultura simbólica, Zamora, El Colegio de M ichoacán/Consejo Nacional de Ciencia y Tecnología, 2002, pp. 215-22I.

31. El dato fue tomado de Juan M anuel de San Vicente, "Exacta descripción de la magnífica corte mexicana, cabeza del nuevo americano mundo, significada por sus essenciales partes, para el bastante conocimiento de su grandeza" (I768), en La ciudad de M éxico en el siglo xVIII ( $6600-1780)$. Tres crónicas, M éxico, Consejo N acional para la Cultura y las Artes, 1990, p. 177.

32. Denuncia sobre unos rótulos con nombres de vinos que al reverso tienen la imagen de Jesús, año de I764. AGN. Fondo Inquisción, vol. 1070, exp. 17, fs. 298-308. 
documentación de la época: "Y ¿qué harán estos holgazanes todo el día en la taberna? U nos ratos parlan cosas ociosas, otros juegan, y de ambos modos no se pasa cuarto de hora sin beber su buen trago." 33

Las vinaterías, lugares en los que se daba rienda suelta a las costumbres relajadas, eran consideradas por las autoridades y la elite gérmenes de subversión social que era necesario eliminar. La política coercitiva dieciochesca buscaba modernizar, reformar e ilustrar a la sociedad; sin embargo, las autoridades confiaban en que para mantener la paz social era indispensable mantener el tradicional orden jerárquico y estamentario de la misma. Su preocupación las llevó a desaprobar una imagen en la que se eliminaba la legitimación de dicho orden, pues la Fortuna no podía ser considerada, como en la Edad M edia, un emblema moral que igual ara a ciertos personajes de la vida pública.

Con la censura, ejercida selectivamente, se reconocía al emblema su eficacia como el aparato propagandístico por excelencia del ordenamiento social. Al mismo tiempo que el género emblemático demostraba sus posibilidades de explotación visual y de adaptación a las variantes históricas de la recepción. ${ }^{34}$

En este caso, las autoridades virreinales dejaron en claro que frente a los excesos eran necesarios los mecanismos de educación y represión. Por ello, aplicaron una vigilancia constante y un control absoluto sobre la imagen, conscientes del profundo poder contenido en su elocuencia silenciosa. 35 \&

33. "Informe sobre pulquerías y tabernas del año de 1784 ", en Boletín del Archivo General de la Nación, t. XVIII, núm. 2, pp. 228-229.

34. C fr. Fernando Rodríguez de la Flor, op. cit., p. 338.

35. Cfr. Fernando Rodríguez de la Flor, La península metafísica. Arte, literatura y pensamiento en la España dela Contrarreforma, M adrid, Biblioteca N ueva, I999, p. 93. 
DOI: http://dx.doi.org/10.22201/iie.18703062e.2003.83.2402

\section{Fuentes documentales}

Archivo General de la N ación. Fondo Inquisición:

D enuncia de un Cristo con una guitarra en la mano, pintado en la pared, año de I609, vol. 284, exp. 95, fs. 790-790V.

Inventario de los bienes del bachiller M iguel de Arana, año de 1732, vol. 839, exp. 23, fS. $28 \mathrm{I}-284$.

Lista de libros presentada por don José Q uinto, librero en la calle de la M onteriIla, año de 1759 , vol. 992, exp. 6, fs. 4I-202.

D enuncia sobre unos rótulos con nombres de vinos que al reverso tienen la imagen de Jesús, año de i764, vol. 1070, exp. 17, fs. 298-308.

D enuncia de un cielo de vinatería, año de I767, vol. 1064, exp. 25, fS. 331-332.

Bibliografía

Alciato, Andrea, Los emblemas, introducción de A. Egido, notas de Santiago Sebastián, M adrid, Akal, 1985.

Baxandall, M ichael, Pintura y vida cotidiana en el Renacimiento, Barcelona, Gustavo Gili, 2000.

Bouzy, Christian, "N eoestoicismo y senequismo en los emblemas morales de Juan de O rozco", en Rafael Zafra y José Javier Azanza (eds.), Emblemata aurea. La emblemática en el artey la literatura del Siglo de O ro, M adrid, Akal, 2000.

Burke, Peter, La cultura popular en la Europa moderna, M adrid, Altaya, I997.

Cárdenas G utiérrez, Salvador, "La 'Rueda de la fortuna': un emblema del Estado moderno", en H erón Pérez y Bárbara Skinfill (eds.), Esplendor y ocaso de la cultura simbólica, Zamora, El Colegio de Michoacán/Consejo Nacional de Ciencia y Tecnología, 2002.

Champeaux, Jacqueline, Fortuna: recherches sur le culte de la fortune à Rome et dans le monderomain desoriginsà la mort de César, Roma, École Française de Rome, 1982.

Curiel, Gustavo y Antonio Rubial, "Los espejos de lo propio: ritos públicos y usos privados en la pintura virreinal", en Pintura y vida cotidiana en M éxico, I650-I950, M éxico, Fomento Cultural Banamex/C onsejo N acional para la Cultura y las Artes, 1999 .

Díaz, Simón J., "La poesía mural del Siglo de 0 ro: su proyección en universidades y colegios", en Estudios sobre el Siglo de O ro. Homenaje a Francisco Yndurain, M adrid, Editora N acional, 1984 . 
Esteban Lorente, Juan F., “La ocasión o 'Parte de fortuna' como tema astrológico en los palacios de la Farnesinia (Roma) y Zaporta (Zaragoza)", en Santiago Sebastián (coord.), Actas del I Simposio Internacional de Emblemática, Teruel, Instituto de Estudios Turulenses, 1994.

Frakes, Jerold C., The Fate of Fortune in the Early M iddleAge, Leiden, E.J. Brill, 1987. Granados Salinas, Rosario Inés, "H acia la puerta norte del salón del estrado", en H erón Pérez y Bárbara Skinfill (eds.), Esplendor y ocaso de la cultura simbólica, Zamora, El Colegio de Michoacán/Consejo Nacional de Ciencia y Tecnología, 2002.

H omero, La 0 disea, M éxico, Porrúa, I99I.

"Informe sobre pulquerías y tabernas del año de I784", en Boletín del Archivo General de la N ación, núm. 2, tomo XVIII, pp. 228-229.

Ledda, Giuseppina, "Estrategias y procedimientos comunicativos en la emblemática aplicada (fiestas y celebraciones, siglo xviI)", en Rafael Zafra y José Javier Azanza (eds.), Emblemata aurea. La emblemática en el arte y la literatura del Siglo de O ro, M adrid, Akal, 2000, pp. 25I-262.

Lombardo de Ruiz, Sonia, Antología de textos sobre la ciudad de M éxico en el periodo de la Ilustración (I788-I792), M éxico, Instituto N acional de Antropología e H istoria-D epartamento de Investigaciones Históricas, 1982 (Colección Científica, Fuentes, $\mathrm{H}$ istoria Social, II3).

M aquiavelo, N icolás, El príncipe, M éxico, Porrúa, 197I.

M artínez del Río de Redo, M arita, "Los biombos en el ámbito doméstico: sus programas moralizadores y didácticos", en Juegos de ingenio y agudeza. La pintura emblemática en la N ueva España, M éxico, Consejo N acional para la Cultura y las Artes, 1994.

M endoza, Juan de Dios, Fortuna y providencia en la literatura castellana del siglo xV, M adrid, Boletín de la Real Academia Española, 1973.

M ínguez, Víctor, "I747-I808: Agonía emblemática. El ocaso de la cultura simbólica en la fiesta novohispana", en H erón Pérez M artínez y Bárbara Skinfill (eds.), Es plendor y ocaso de la cultura simbólica, Zamora, El C olegio de M ichoacán, 2002, pp. 303-315

—, Emblemática y cultura simbólica en la Valencia barroca. Jeroglíficos, enigmas, divisas y laberintos, Valencia, Edicions Alfons el M agnànim, 1997.

M orán, M iguel y Javier Portús, El arte de mirar. La pintura y su público en la España deVelázquez, M adrid, Istmo, 1997.

O vidio, Publio N asón, M etamorfosis, M adrid, Alianza, 2000. 
Palomino de Castro y Antonio Velasco, El museo pictórico y escala óptica, tomo II, M adrid, Viuda de Juan García Infançon, 1724.

Panofsky, Erwin, "La historia primitiva del hombre en dos ciclos de pinturas de Piero di Cósimo", en Estudios sobre iconología, M adrid, Alianza, 1998.

Patch, H oward R., The Goddes Fortuna in M ediaeval Literature, Cambridge, $\mathrm{H}$ arvard U niversity Press, 1927.

Pérez-M archand, M onelisa, D os etapas ideológicas del siglo xvIII en M éxico a través de los papeles de la Inquisición, M éxico, El Colegio de M éxico, 1945.

Revilla, Federico, "M aterial emblemático en la vía pública: su presencia en una de las fiestas dieciochescas de Barcelona", en Víctor Mínguez (ed.), Del libro de emblemas a la ciudad simbólica. Actas del III Simposio Internacional de Emblemática H ispánica, C astellón de la Plana, Universitat Jaume I, 2000, vol. I.

Ripa, Cesare, I conología, Venecia, Cristóforo Tomasini, I645, t. I, libro segundo.

Rodríguez de la Flor, Fernando, Emblemas. Lecturas de la imagen simbólica, M adrid, Alianza, 1995.

_- La península metafísica. Arte, literatura y pensamiento en la España de la Contrarreforma, M adrid, Biblioteca N ueva, 1999.

San Vicente, Juan M anuel de, "Exacta descripción de la magnífica corte mexicana, cabeza del nuevo americano mundo, significada por sus essenciales partes, para el bastante conocimiento de su grandeza" (I768), en La ciudad de M éxico en el siglo XVIII (I690-I780). Tres crónicas, M éxico, Consejo N acional para la Cultura y las Artes, 1990.

Sebastián, Santiago, I conografía e iconología del arte novohispano, M éxico, Grupo Azabache, 1992.

__ "Los libros de emblemas: uso y difusión en Iberoamérica", en Juegos de ingenio y agudeza. La pintura emblemática en la N ueva España, M éxico, Consejo $\mathrm{N}$ acional para la Cultura y las Artes, 1994.

- Emblemática ehistoria del arte, M adrid, Cátedra, I995.

Toussaint, M anuel, Pintura colonial en M éxico, M éxico, Universidad N acional Autónoma de $M$ éxico-Instituto de Investigaciones Estéticas, 1965.

Viqueira Albán, Juan Pedro, iRelajados o reprimidos? Diversiones públicas y vida social en la ciudad de M éxico durante el Siglo de las Luces, M éxico, Fondo de Cultura Económica, 20oI. 